\title{
The Tostan story: Breakthrough in Senegal ending female genital cutting [Arabic]
}

Population Council

Follow this and additional works at: https://knowledgecommons.popcouncil.org/departments_sbsr-rh

Part of the Community-Based Research Commons, Gender and Sexuality Commons, International Public Health Commons, Maternal and Child Health Commons, Obstetrics and Gynecology Commons, Public Health Education and Promotion Commons, and the Women's Health Commons How does access to this work benefit you? Let us know!

\section{Recommended Citation}

"The Tostan story: Breakthrough in Senegal ending female genital cutting [Arabic]," FRONTIERS Report. Cairo: Population Council, 1999. 


\section{(2) Population Council \\ $\eta$ Frontiers}

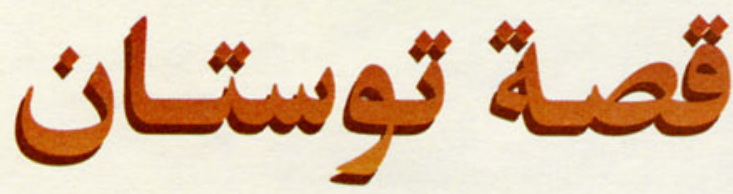

القضاء على ختان الإخاث فى اس قرية بالسنغال
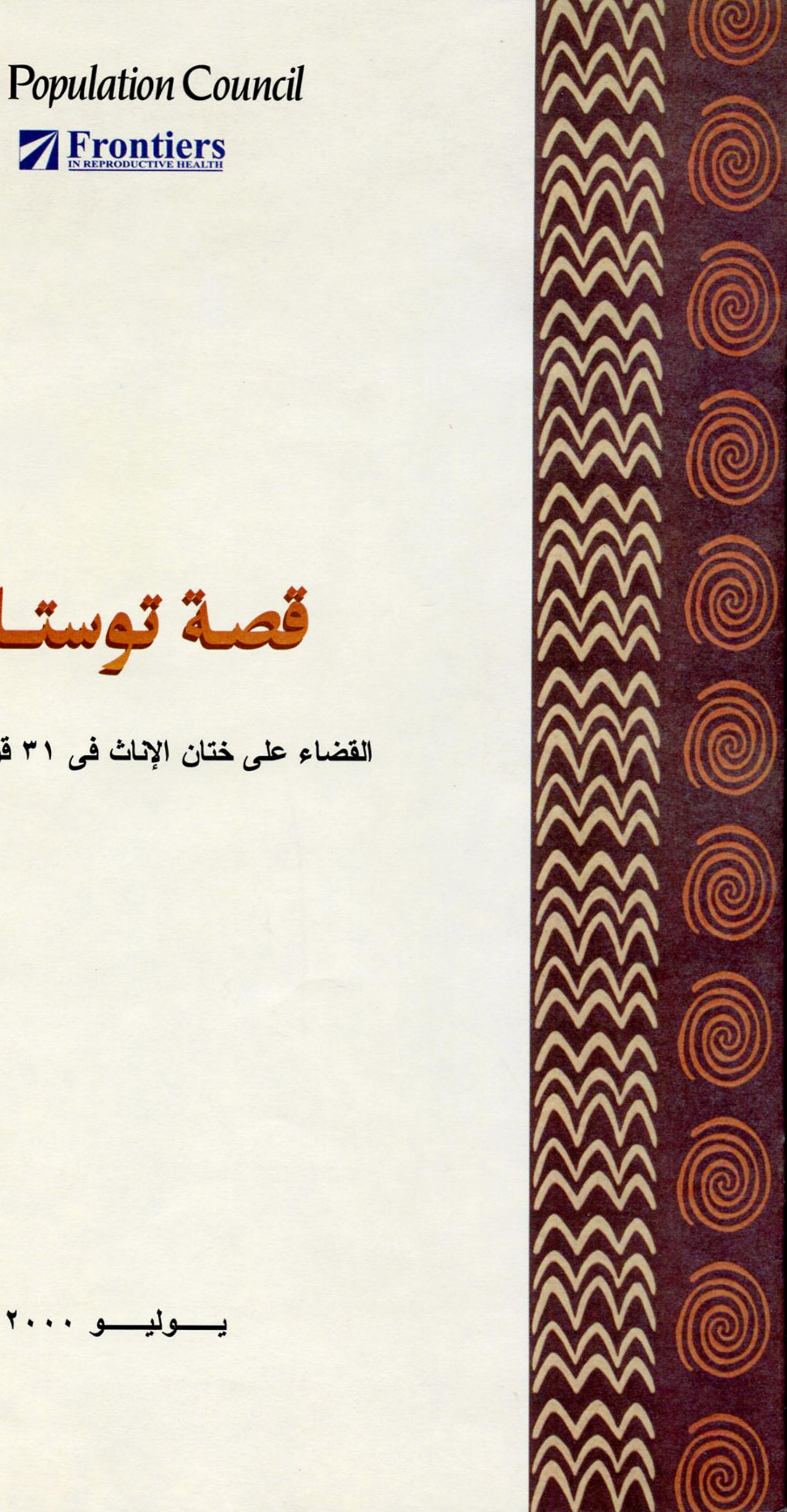


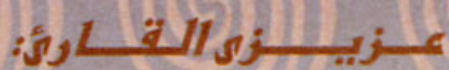

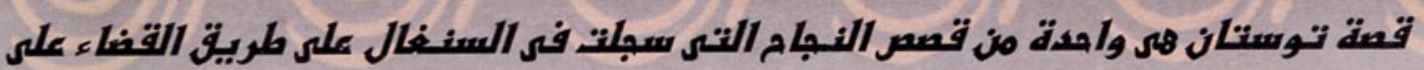

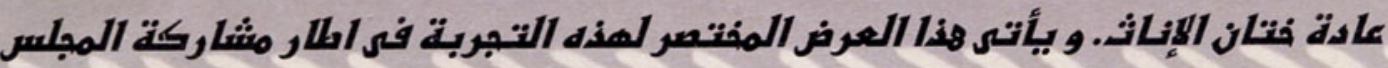

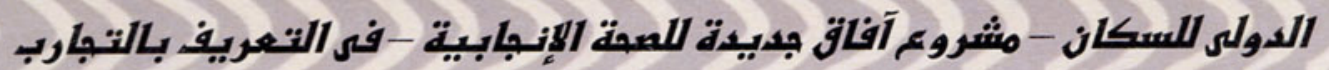
المفتلفة و نتائج البهوث و الدراسات سواء أكان داخل مصر او خاربها والمرتبطة

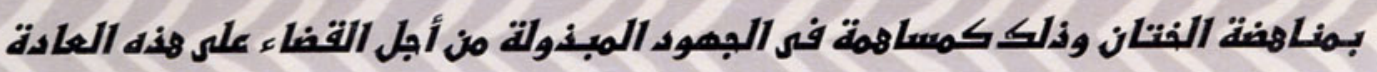
آمليز ان تبدوا هذه الدراسات و التبارب مفيدة.

$$
\text { القضاء على ختان الإناث في اس قرية في السنغال }
$$

في يوليو 1997، أعلنت •ـ امرأة من قرية "ماليكونا بامبارا" السنغالية أمام وفد من

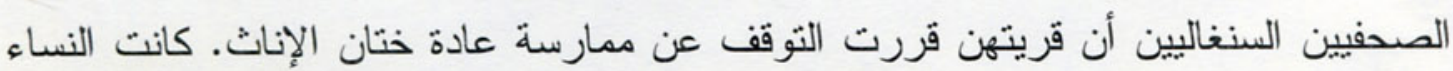

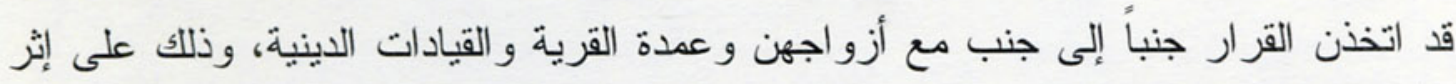

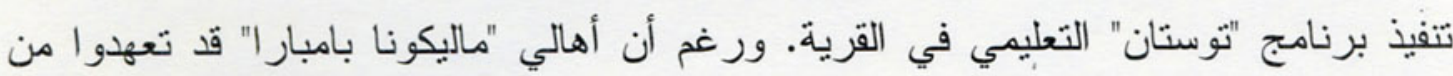

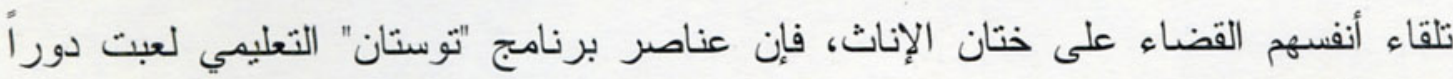

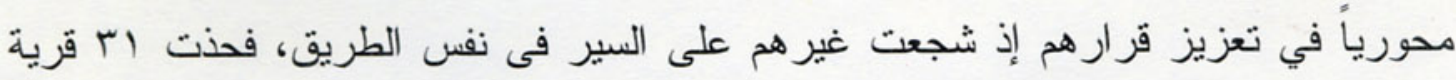

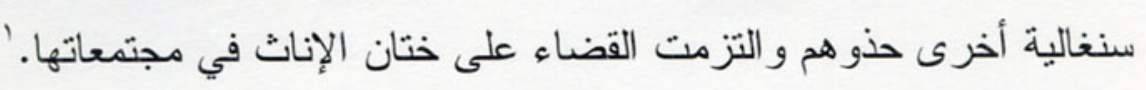

عند اتخاذ قرارهن التاريخي بالقضاء على ختان الإناث أثشارت نساء "ماليكونا بامبار ا" إلى ألى

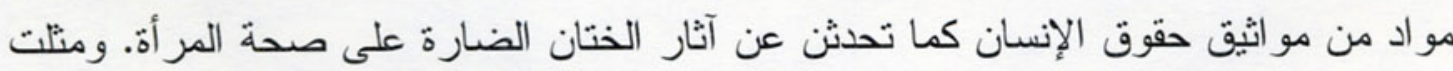

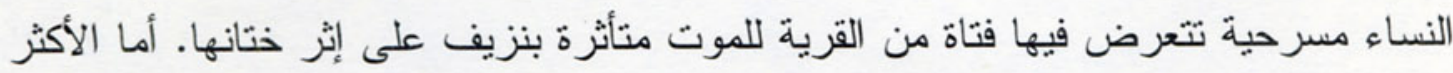

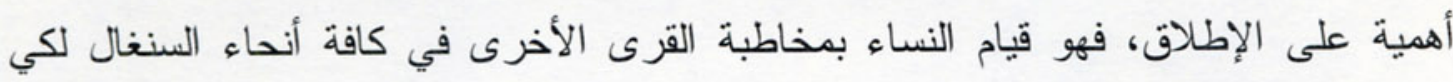
يحذو حذو هن.

برنامج توستان التعليمي تعني كلمة "توستان" بلغة "وولوف" السنغالية "اختراق" أو "قفزة للأمام". و "توستان" هي

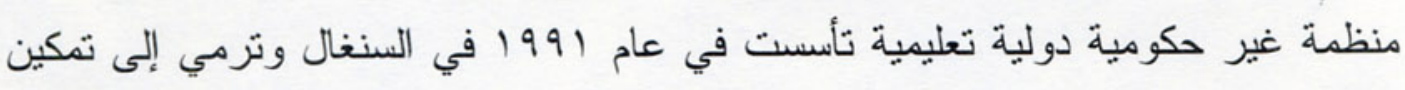

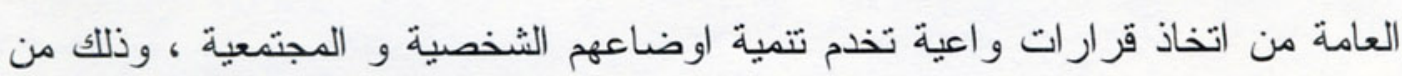

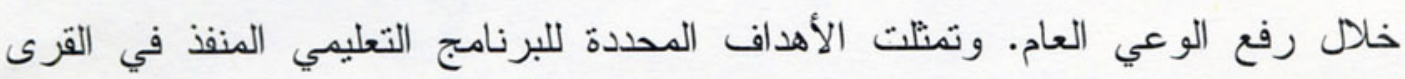
السنغالية فيما يلي:

لم ينفذ برنامج توستان في كافة القرى الإحدى والثلائين التي قررت القضاء على ختان الإناث. بيد أن انتشار المعلومات حول اليرنامج من حلال الحركة

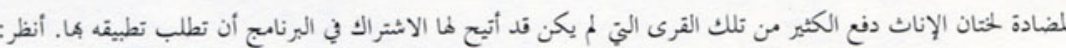
Tostan, Breakthrough in Senegal - Ending Female Genital Cutting, Population Council, January 1999, p. 65 . 


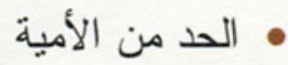

• تعزيز التتمية الذاتية من خلال استخدام المواد التعليمية الملائمة

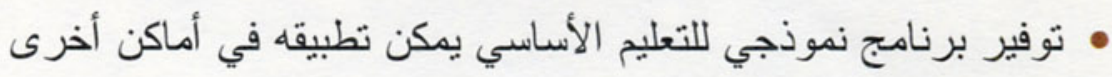

ومن المهم الإشارة إلى أن برنامج توستان الذي دفع القرى السنغالية للقضاء على ختان الإناث

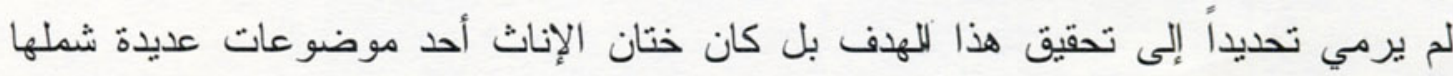

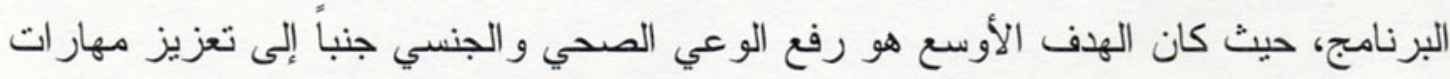

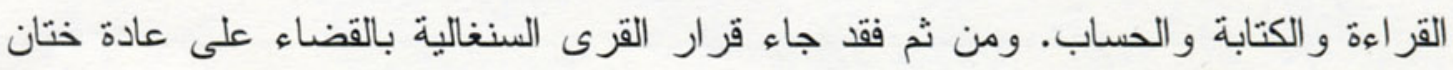
الإناث كمفاجأة كبيرة - و إن كانت سارة بالطبع ــ للعاملين ببرنامج توستان.

يتضمن برنامج نوستان مكوتنين رئيسيين. يرمى الأول إلى تطوير المهارات والمعارف

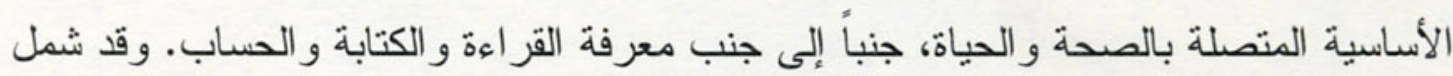

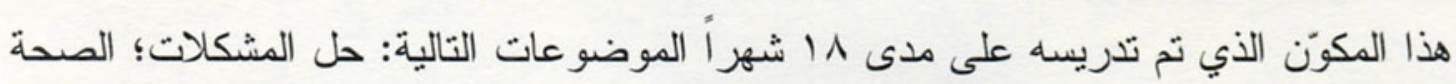

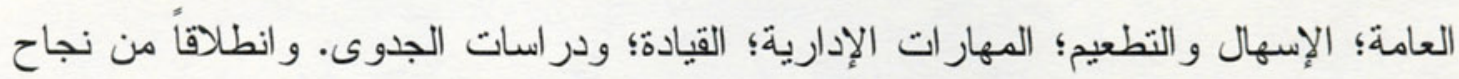

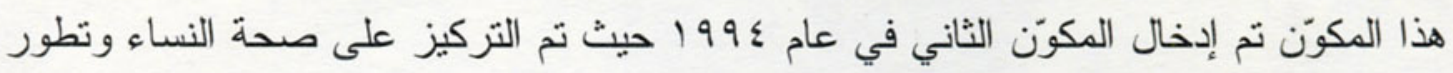
الطفولة المبكرة. و رمى هذا المكوّن إلى تحسين الأحوال البدنبة و النفسية للنساء و الأطفال السنغاليين بغض النظر عن مهار ات القز اءة و الكتابة.

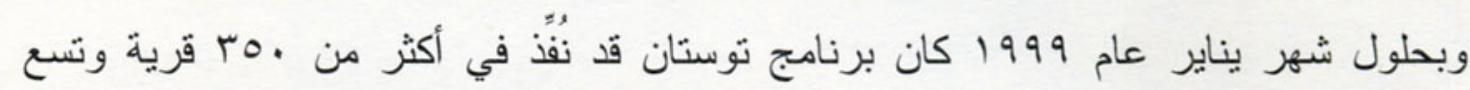

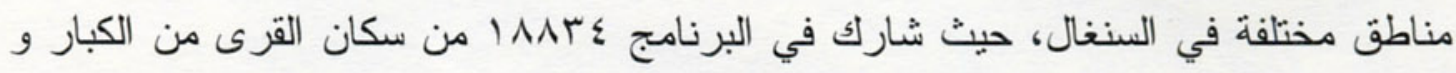

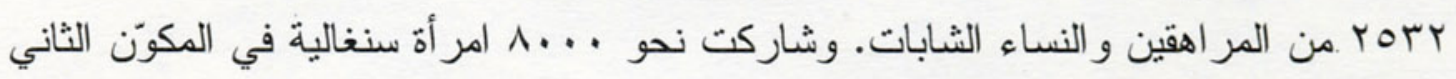

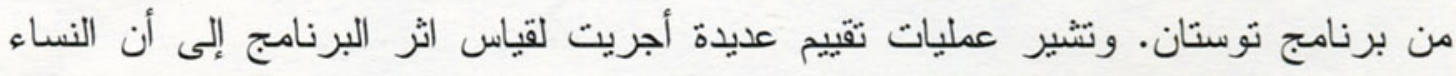

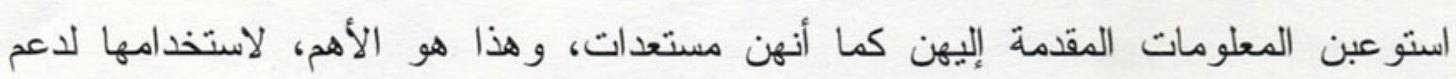

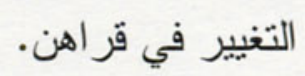

برنامج توستان وختان الإناث على الرغم من التردد في البداية بسبب الحساسيات الثقافية، نم إدخال ختان الإناث كموضو ع عالثات

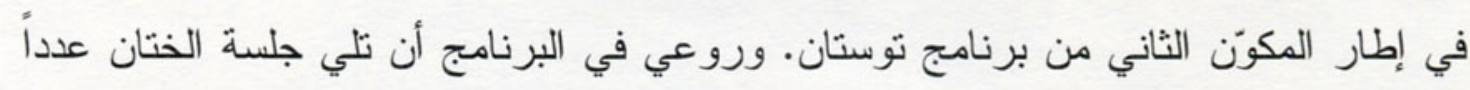

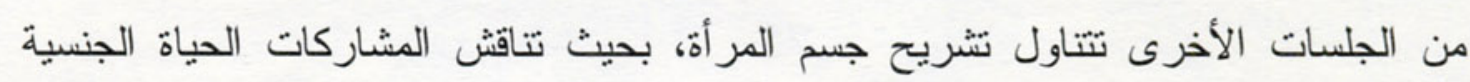

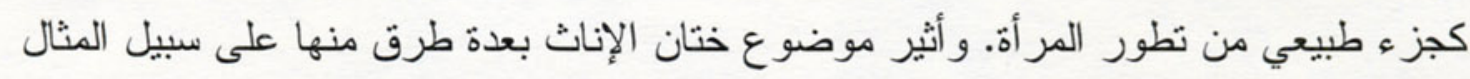

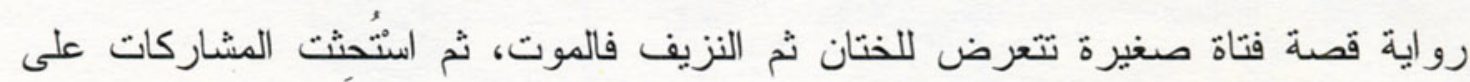

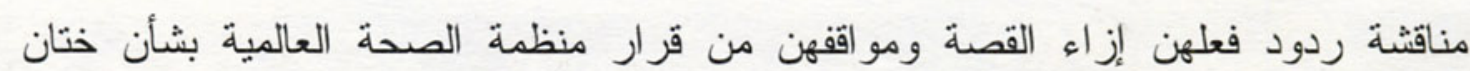


قرار قرية "ماليكونا بامبارا" القضاء على ختان الآناث

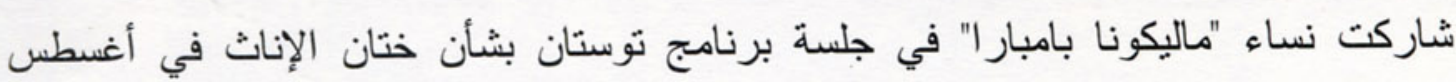

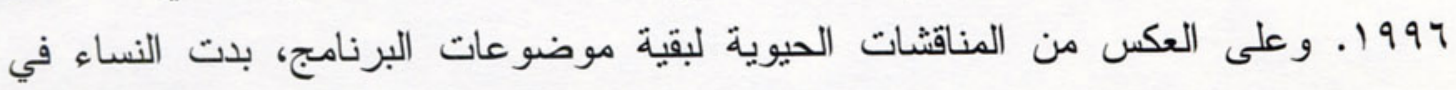

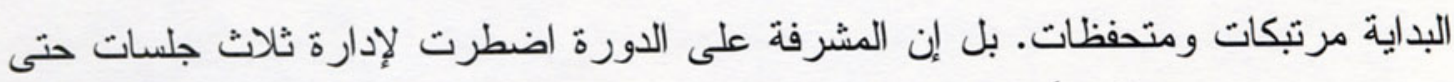

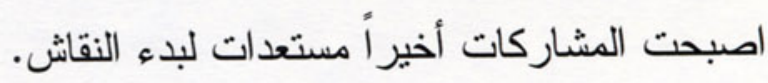

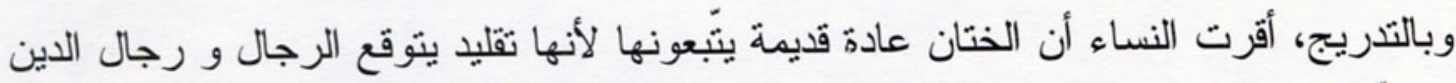

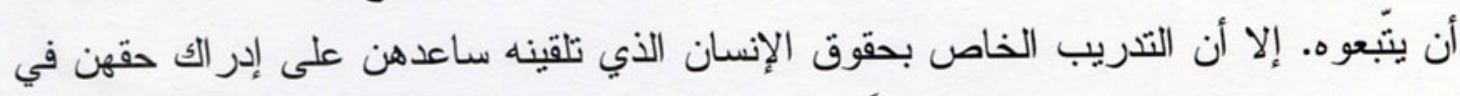

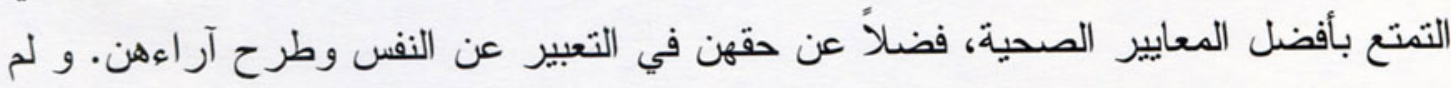

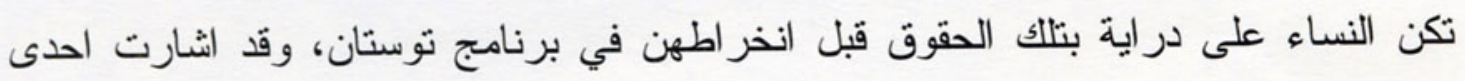

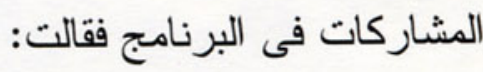

\section{"بأنا التفكير والحديث في الفصل حول أشياء لم بسبق لنا

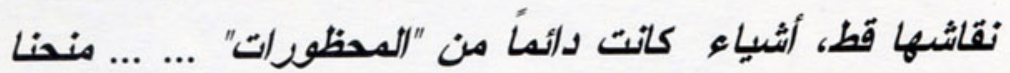 برنامج توستان مقدراً من الثقة لم بكن متوافراً لنا من قبل.

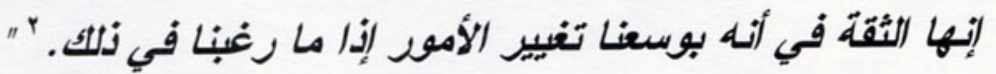

أصبحت نساء "ماليكونا بامبار ا" في النهاية حريصات للغاية على نقاش الموضوعات المحيطة

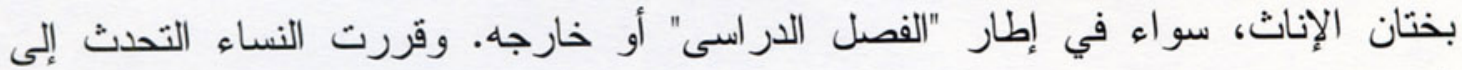

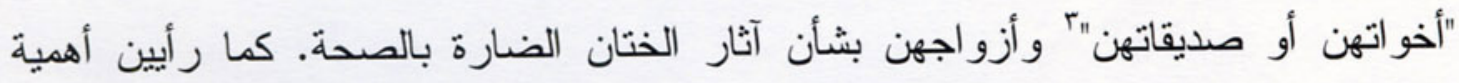

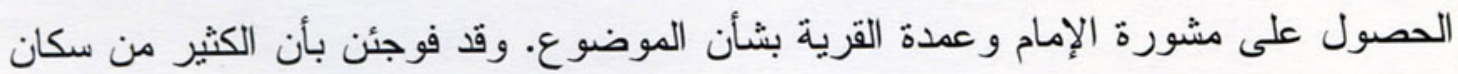

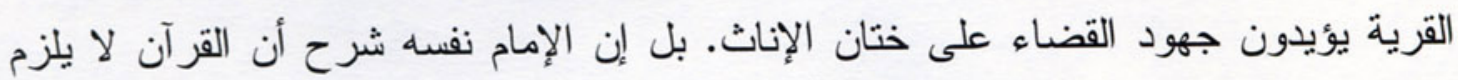

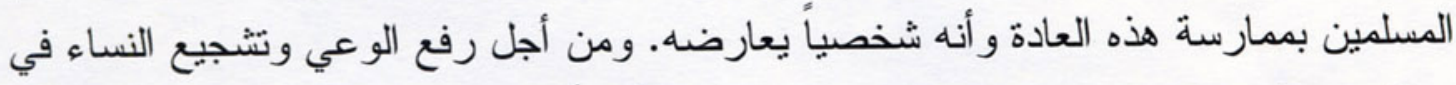

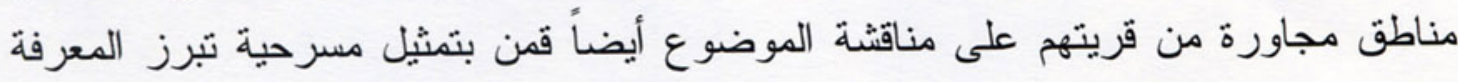

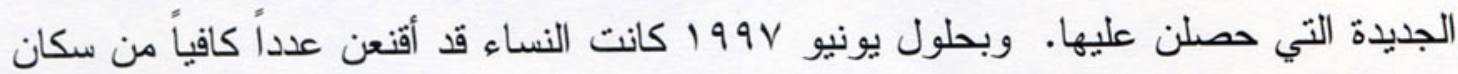

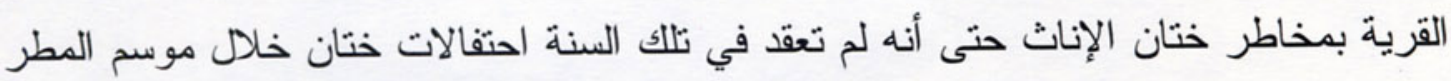

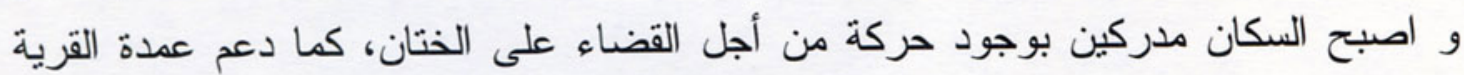

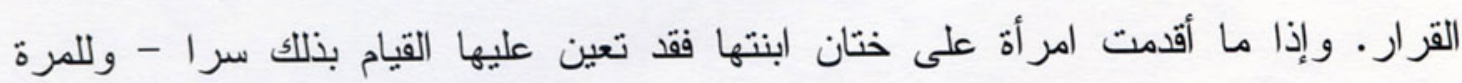

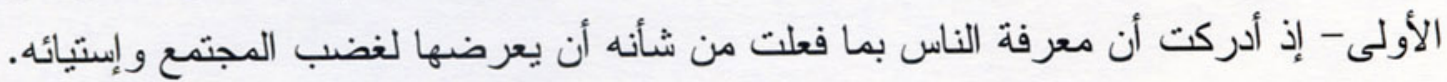




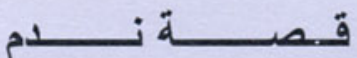

أثناء اجتماع أهلي في قربية "نجوريني" بــبامبارا" ذكرت "أوريي سال"

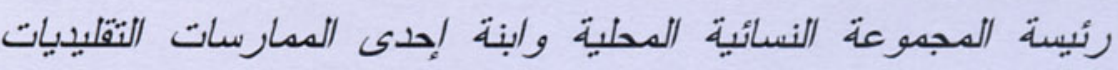

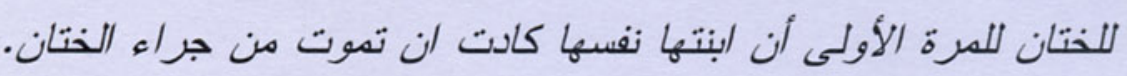

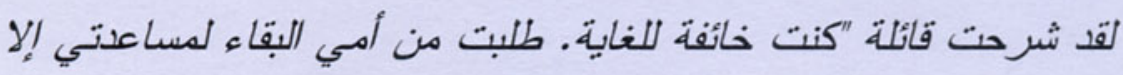

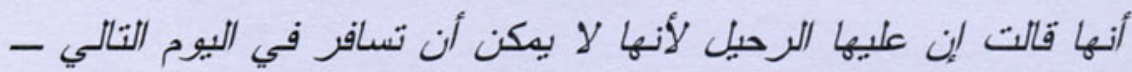

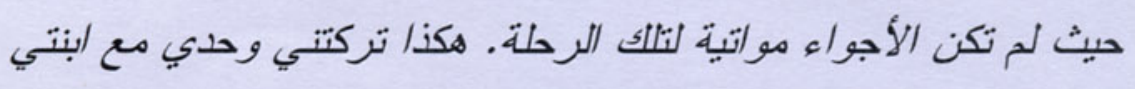
التى كانت تنزف. حاولت استخدم وسائل وقف النزيف التقليدية بلا لأل

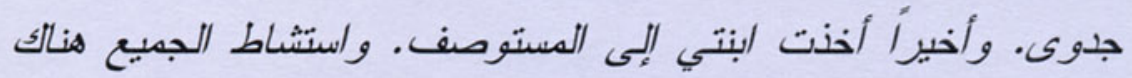

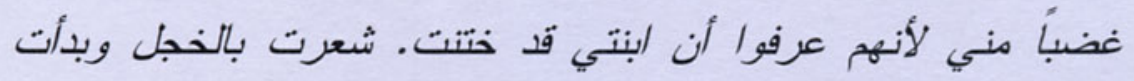

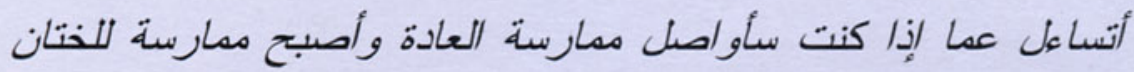

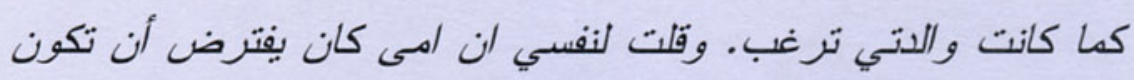

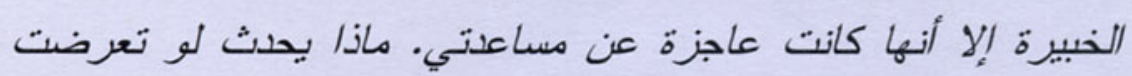

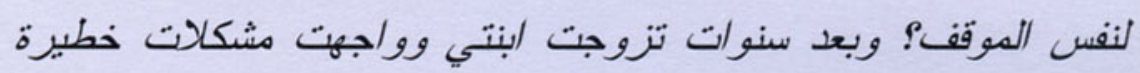

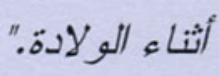

بلغ ارتباح سكان قرية

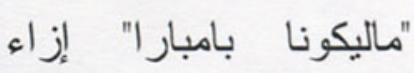
قر ارهم القضاء على ختان الإناث حده في نهاية

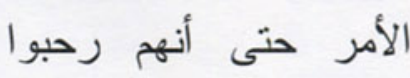

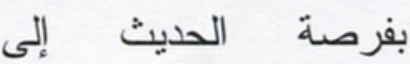
الصحفيين السنغاليين وممنلي الحكومة. و وأعقب ذلك تغطية إعلامية على وملى واعلى

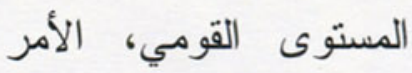

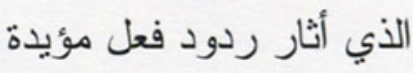

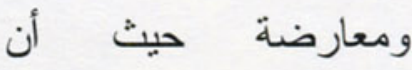
الاهتمام الذي أثثاره قرار قرية "ماليكونا بامبار ا" قد لقد

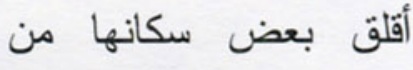

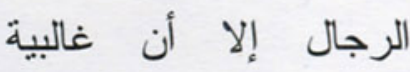
النساء حافظن على ثقتهن

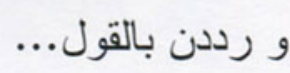

"رغم اعترافنا بأنه بحق لهم (الرجال المعارضون للإعلان)

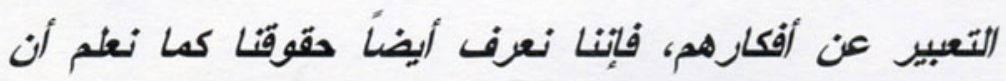

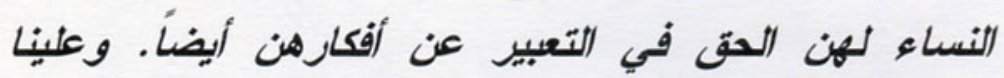

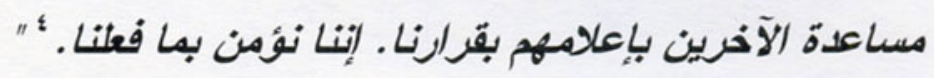

\section{قرار قرى سنغالية أخرى القضاء على ختان الإناث} لقد ساعد الالتزام التاريخي من جانب قرية "ماليكونا بامبارا" لرفض ممارسة الختان دعم مجتمعات محلية سنغالية أخرى على بدء النشكيك ومن ثم رفض ممارسة ختان الإناث.

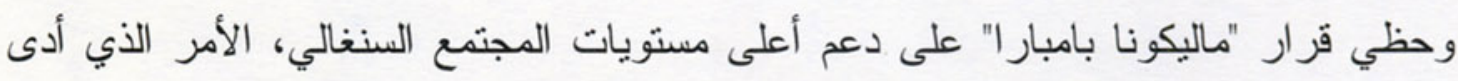

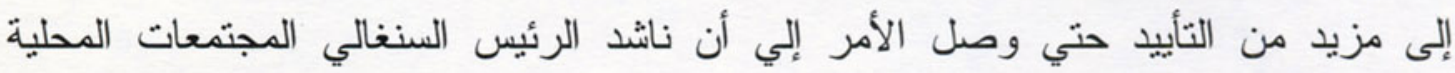
ألأخرى الاقتداء بهذا المثال وبدأ في إجر اءات لسن قانون ضد لأند ختان الإناث. 
كان هنالك اجماع بأن إقناع مجتمعات أخرى بالقضاء على ختان الإناث يعد ضرورياً من أجل ايجاد قاعدة واسعة لتغيير المواقف، بحيث تتحرر الفتيات غير المختتات من التحيز ضدهن

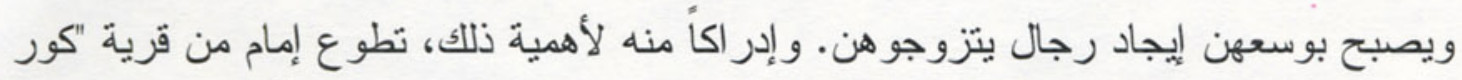

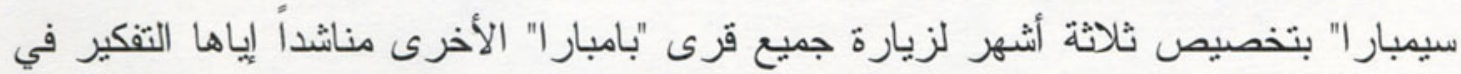

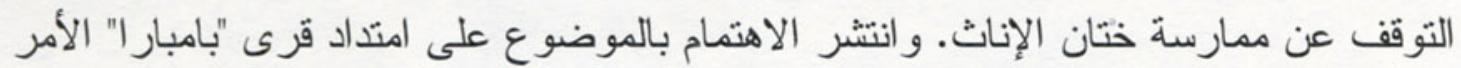

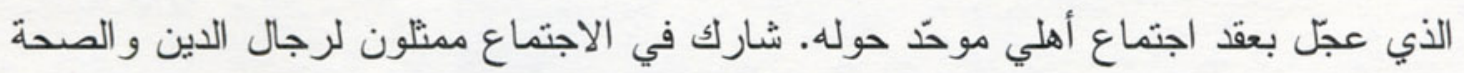
و الحكومة، وعلى إثر الكثير من النقاش وتبادل المعلومات أصدر مجتمع "بامبار ا" إعلانه التاريخي المعروف بإعلان ديابوجو، و والذي ورد فيه هذا التعهد: "تتعهُ نحن أهالمي "بامبارا" بالقضاء على مدارسة ختان الإناث

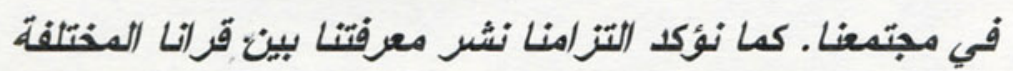

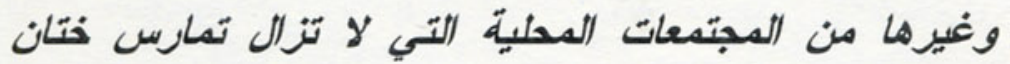
الإناث." و

تُرْجِم إعلان ديابوجو بعد ذللك إلى اللغات السنغالية الأخرى و أُدْمج في بر امج توستان التُعليمية

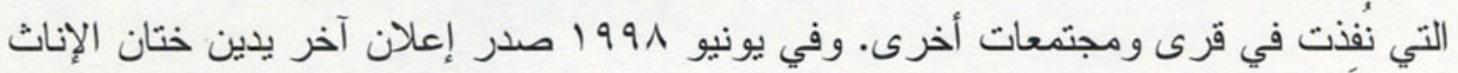
ووقعته قرى مقاطعة "فو لادو" السنغالية الثمان عشرة. وبحلول يناير 1999 كانت اب قرية لحتية

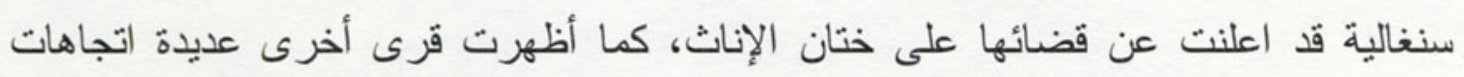
و اعدة بنفس المفهوم. وفضلاً عما سبق، برهنت التعهدات الأهلية على تمتعها بالتواصل

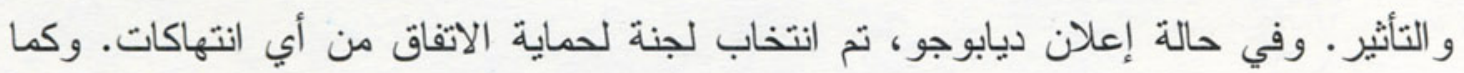
لاحظ إمام "بامبار ا" الذي يحظى بالتأثير :

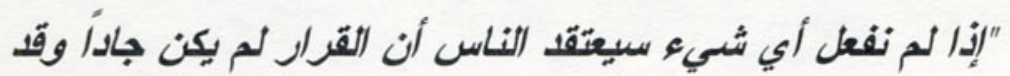

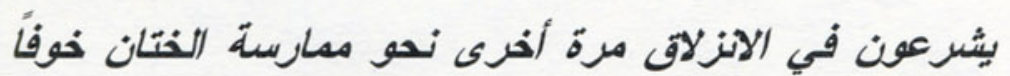

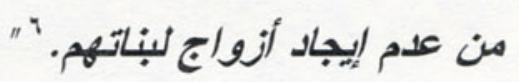

عو امل أساسية وراء نجاح برنامج توستان من الواضح أن الحصول على النعليم الأساسي كان عاملاً حاسماً في القضاء على على خلى ختان

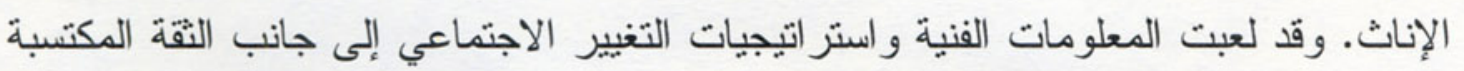

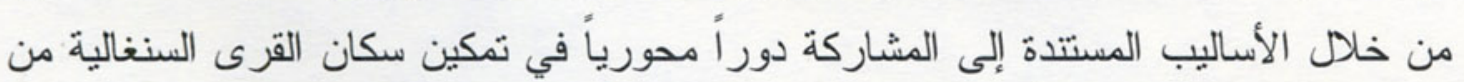

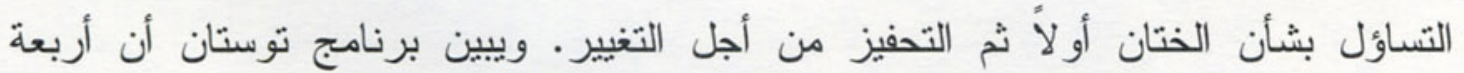
اسنز اتيجيات أساسية كانت محورية لنجاح البرنامج: 


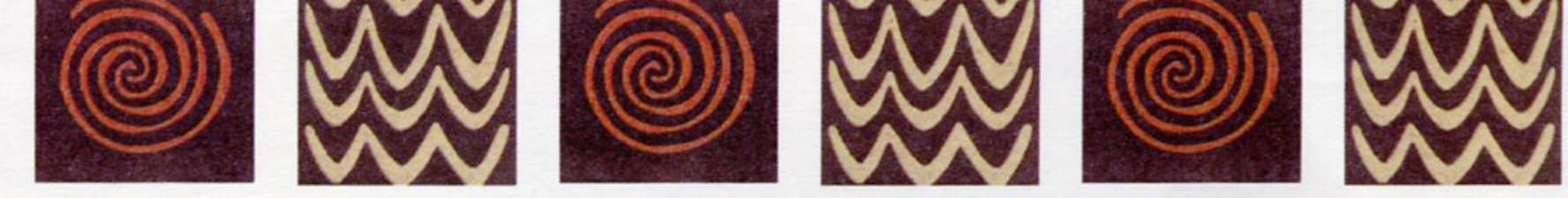

أ. برنامج تعليمي شامل يؤكد على الكيف فضلاً عن استخدام منهج شامل للتعلم يعزز الممارسات و القيم الثقافية الإيجابية

ب. برنامج سهل و في منتاول الدارسات من النساء يستخدم تجاربهن و بشجعهن على مشاركة المعلومات مع الأصدقاء و الأقارب

ج· برنامج يمكن استخدامه بو اسطة منظمات وبلدان أفريقية أخرى

د. منهج يستتد إلى المشاركة و برمي إلى تعزيز التتمية الذاتية ويؤكد على الاستر اتيجيات السلمبة للتغيير الاجتماعي

و إضافة إلى ذلك أبرز الرجال و النساء السنغاليون الأكثر انخر اطاً في عملية القضاء على ختان الإناث جو انب البرنامج العلمية التالية بوصفها ذات قيمة خاصة بالنسبة لقضيتهم:

$$
\begin{aligned}
& \text { • حل المثكلات } \\
& \text { • الصحة العامة وفهم كيفية انتقال الجر اثيم } \\
& \text { • المهار ات القيادية من أجل اتخاذ القرار ات المهمة و الدفاع عنها } \\
& \text { • المعلومات الصحية و التشريحية الأساسية } \\
& \text { • الصحة الجنسية } \\
& \text { • تعلم اسنز اتيجيات التغيير الاجتماعي }
\end{aligned}
$$

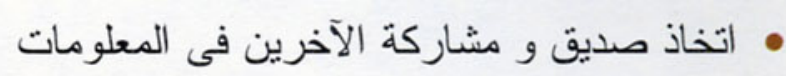

$$
\begin{aligned}
& \text { • ربط المعرفة بالفعل وتم } \\
& \text { • التعرف على حقوق الإنسان }
\end{aligned}
$$

النتائج و الأروس المستخلصة

يُقِر القائمون على منظمة توستان بأن ثمة عو امل خارجية أسهمت في التوقف عن ممارسة الختان في القرى السنغالية. كان الوقت "ملائماً للتغيير" إذ دعت جماعات النساء وحقوف الإنسان على مدى سنوات عديدة للتوقف عن ممارسة ختان الإناث وبدأث هذه الرسالة نصل ببطء إلىى مستوى القرية. كما كانت المشاركة الإيجابية للقيادات الدينية حاسمة أيضاً، خاصة

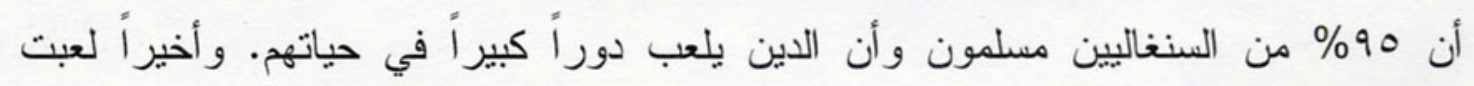
التصريحات العامة عن قرار القضاء على الختان دوراً بالغ الأهمية في التأثير على القرى الأخرى لأخذ الموقف ذاته، الأمر الذي خلق "كتلة مؤثرة" من المجتمعات المحلية الملتزمة بالقر ار والتي لا برجح بالتالي أن نظهر التحيز ضد الفتيات غير المختتات. 
